\title{
DAS PENAS PRINCIPAIS E SUA APLICAÇÃO
}

\author{
BASILEU GARCIA
}

1. - Entendo que esta série de palestras tem um objetivo prático: descobrir os eventuais defeitos da remodelação penal esboçada, com o brilho de sempre, pelo Ministro NELSON HUNGRIA, o que é um meio de prestar colaboração, embora discreta, ao ilustre jurista. Quanto às virtudes do seu trabalho, não será indispensável mencioná-las a cada passo. O silêncio valerá como aplauso ou concordância. Poderá também, uma ou outra vez, significar que os reparos cabíveis a propósito de determinado ponto seriam de muito pequena monta. As críticas resultarão prestantes se forem julgadas procedentes.

2. - No setor que me coube para o exame que ora empreendo, o das penas principais e sua aplicação; discordo inicialmente do teor do art. 35 (1) que formula uma profissão de fé finalística, a meu ver excrescente num corpo de leis e destoante da realidade. Não adianta dizer, como diz êsse artigo, que as penas de reclusão e detenção "devem ser executadas de modo que exerçam sôbre o condednao uma individualizada ação educacional, no sentido de sua gradativa recuperação social", nem é eficaz a designação marginal ao texto, "função finalística das penas privativas de liberdade", se $\circ$ anteprojeto dá reiterado testemunho de que reconhece, ecléticamente, como é natural, tudo quanto constitui escopo da pena, da qual também são inapartáveis o caráter retributivo e o de meio de intimidação.

O próprio art. 35 declara que o regime de pena de reclusão é mais rigoroso que o da detenção, o que indica que visa castigar mais, tendo em mira circunstâncias que reclamam severidade maior. $E$, adiante, no $\S 1 .^{\circ},(2)$ menciona-se que a reclusão tem o mínimo de

(1) - Art. 35 - A pena de reclusão e a de detenção, aquela sob regime mais rigoroso que esta, são cumpridas em estabelecimentos separados ou em seções especiais do mesmo estabelecimento, e devem ser executadas de modo que exerçam sôbre o condenado uma individualizada ação educacional, no sentido de sua gradativa recuperação social.

(2) - § 1.0 - 0 mínimo da pena de reclusão é de um ano e o máximo, de 40 anos; o mínimo da pena de detenção é de 15 dias, e o máximo, de 20 anos. 
um ano e a dentenção o mínimo de 15 dias. Ainda, no art. 37 (3) pre. vê-se a imposição de pena a indivíduo de "nenhuma" periculosidade. Inspirará a pena, em tais hipóteses, o desiderato de uma "ação educacional", que ora não é exequível pela brevidade do tempo, ora não se faz mister? E' óbvio que o codificador, ao mandar impô-la então, estará exclusivamente querendo punir e intimidar, a bem da prevenção não só especial como geral.

3. - Não me demoraria nesse aspecto teórico se, em primeiro lugar, não fôsse desaconselhável incluir preceitos de cunho doutrinário e de inclinação pessoal num estatuto repressivo; se, em segundo lugar, não pudesse aquela advertência ser aproveitada para o desencorajamento da repressão; e se, finalmente, o anteprojeto não extraísse dela um corolário tão relevante quanto desvantajoso.

Servirá para fomentar soluções de complacência em detrimento da defesa social. Se o legislador faz supor que as penas privativas da liberdade não têm outro fim senão o de educação e recuperação, alegar-se-á, com certa plausibilidade, ser escusado infligí-las em pról de outros interêsses, e a absolvição será o coroamento de crimes demonstrados, cometidos todavia por agentes que parecem não precisar o influxo moralizador de âmbito individual cogitado no texto.

A consequência que o Ministro NELSON HUNGRIA retira do princípio doutrinário incorporado à proịetada legislação surge na sua frase explicativa: "Assim definida a função finalística da pena privativa de liberdade, identifica-se esta com a medida de segurança detentiva. A manutenção desta, como sanção distinta daquela, só se justifica num caso: quando o condenado necessita de especial tratamento curativo - v. artigo $89^{\prime \prime}$. E efetua cortes substanciais, que considero inconvenientes, na antiga estrutura jurídica das medidas de segurança, cuja utilidade na proteção coletiva é incontestável. Sabe-se que elạs não têm tido uma adequada atuação, por falta de aparelhamento. Cabe, porém, reclamar para que a tenham, e não eliminá-las em nome de um ponto de vista abstrato e discutibilíssimo.

4. - Não compreendo porque só no caso do art. 89 a medida de segurança é mantida "como sanção distinta" da pena privativa de liberdade. Vejo, ao revés, que no art. 89 há confusão entre pena e medida de segurança. $O$ art. 30 , parágrafo único, semelhante ao atual art. 22, parágrafo único, acena com pena reduzida para os se. mi-responsáveis, e o art. 89 completa a disciplina da matéria informando que, "quando o condenado se enquadra no parágrafo único do art. 30 e necessita de especial tratamento curativo, a pena privativa de liberdade é substituida pela internação em estabelecimento psiquiátrico anexo ao manicômio judiciário ou ao estabelecimento

(3) - Art. 37 - As penas de reclusão e de detenção podem ser cumpridas em estabelecimento penal aberto, sob regime de semi-liberdade e confiança, desde que o condenado é primário e de nenhuma ou escassa periculosidade, e a duração da pena não é superior a 5 anos. 
penal, ou em seção especial de um ou de outro". Afinal, a pena, aí, se consubstancia na medida de segurança. Esta substitui aquela. Como pertender que são distintas?

E tanto se confundem nessa hipótese, que o $\S 1 .^{\circ}$ do art. 89 insiste: "Sobrevindo a cura, não se dá a transferência do internado para o estabelecimento penal, mas não fica excluído o seu direito a livramento condicional, como se estivesse a cumprir a substituída pena privativa de liberdade".

Está cumprindo-a, em verdade: pois foi condenado a uma pena e tem até direito a livramento condicional, pertinente às penas de prisão. E a que título é retido o condenado que já se curou, senão em virtude de uma pena?

Aí reaparece a pena-castigo.

5. - Desejo manifestar, prevalecendo-me da associação de idéias, pôsto exceda esta objeção ao meu tema, que as alterações trazidas para o setor das medidas de segurança não deviam ter a profundidade que tiveram. Repare-se, por exemplo, que uma ameaçadora brecha no sólido mecanismo em vigor com relação aos absolvidos por inimputabilidade absoluta se abre no art. 88 do anteprojeto, in verbis: "Quando o agente é penalmente irresponsável (art. 30), mas oferece perigo à segurança pública, o juiz determina sua internação em manicômio judiciário".

Fica, assim, a cargo do juiz, ao absolver o irresponsável, mandá-lo ou não para o estabelecimento de medida de segurança. Nem bastará para essa providência o perigo do sujeito ativo conforme a compreensão corrente, pois será preciso que ofereça, dramàticamente, perigo para a "segurança pública". Isso dará ensejo a muita alegação de distúrbios psíquicos destinados a perdurar até a data do julgamento. Encher-se-á de atrativos a dirimente nas defesas criminais. Será viável invocá-la sem muito risco de, livrando o réu da prisão, colocá-lo sucedâneamente no manicômio. E mais larga é a tolerância quando se observa que o texto da dirimente no anteprojeto (art. 30) está longe de apresentar o louvável rigorismo da redação do Código, que neste passo não tinha a menor necessidade de ser modificado (4).

\section{6. - Reza o $\S 3 .^{\circ}$ do art. 35 que o isolamento celular não é}

(4) - Proceda-se ao cotejo dos dois textos. No Código: Art. 22. E' isento de pena o agente que, por doença mental ou desenvolvimento mental incompleto ou retardado, era, ao tempo da ação ou da omissão, inteiramente incapaz de entender o caráter criminoso do fato ou de determinar-se de acôrdo com êsse entendimento. No anteprojeto: Art. 30. Não é penalmente responsável quem, no momento da ação ou omissão, não possui, em virtude de mórbida perturbação mental, de desenvolvimento mental incompleto ou retardado ou de outra grave anomalia psíquica, a capacidade de entender o caráter ilícito do fato ou de governar a própria conduta.

Mórbida "perturbação" mental é um enunciado mais fraco que "doença" mental e a locução "outra grave anomalia psíquica" padece de uma generalidade que poderá ser perniciosa. 
permitido fora das horas do repouso noturno. Também aqui é preferível o Código, que ressalva a possibilidade de isolamento durante o dia quando o exige interêsse relevante da disciplina. E' fácil imaginar situações em que a administração presidiária necessita, sem outra alternativa, segregar o sentenciado na sua cela durante o dia, para contê-lo em demonstração de violência que outras medidas disciplinares seriam insuficientes para debelar.

7. - O art. 37 (5) alude, vagamente, ao regime de semi-liberdade. Seria de bom aviso uma conceituação delimitada, que explicasse até onde devem ir as regalias, de modo a que na prática não haja formas conflitantes ou abusivas de execução. Convém que se evitem excessos de liberalidade, capazes de converter a pena numa caricatura, nociva à prevenção e até capaz de constituir um convite ao crime.

8. - No art. 39 (6) favorece-se o condenado com o cômputo, de todo justo, do tempo em excesso em que esteve prêso por outro crime. Opino pela mudança de redação dessa norma. Não percebo razão para só o beneficiar o excesso que houver sido proclamado em decisões dos tribunais superiores. Casos haverá em que, mesmo sem recurso a êsses tribunais, a demasia se patenteie, cumprindo que a aquilate o juiz da execução.

A frase que termina êsse dispositivo - "desde que a decisão seja posterior ao crime de que se trata" - é pouco clara. Quer evitar que o condenado se julgue titular de um crédito penal a fazer valer no futuro, com algum crime a cometer adrede para aproveitar o saldo... Mas não é difícil exprimí-lo de modo mais compreensível do que o que foi usado. vações:

9. - No tocante à pena de multa, aduzirei umas poucas obser-

Diga-se, no parágrafo único do art. 42 (7), ao invés de "algarismo do dia-multa", "quantia correspondente ao dia-multa". Ponha-se a quantidade máxima de $\mathrm{Cr} \$ 5.000,00$ em têrmos de salário mínimo, como foi feito com o limite inferior. Mantida como máximo a cifra de $\mathrm{Cr} \$ 5.000,00$, talvez aconteça que daqui a alguns anos o extremo inferior (salário mínimo de um dia) se torne, paradoxalmente, superior ao gráu máximo de $\mathrm{Cr} \$ 5.000,00 \ldots$ No mesmo dispositi-

(5) - Transcrito retro, nota n.० 3.

(6) - Art. 39 - Computam-se na pena privativa de liberdade o tempo de prisão preventiva ou provisória, no Brasil ou no estrangeiro, e o de internação em hospital ou manicômio, bem como o excesso de tempo, reconhecido em grau de recurso ou revisão, ou em "habeas-corpus", na pena cumprida por outro crime, desde que a decisão seja posterior ao crime de que se trata. (7) - Art. 42 - A pena de multa consiste no pagamento, ao Tesouro Nacional, de uma soma de dinheiro, que é fixada em dias-multa. Seu montante é, no mínimo, um dia-multa e, no máximo, 300 dias-multa.

Parágrafo único - O algarismo do dia-multa é fixado segundo o prudente arbítrio do ¡uiz, devendo êste ter em conta as condições pessoais e econômicas do condenado, mas não pode ser inferior ao salário mínimo diário da região nem superior a Cr $\$ 5.000,00$. 
vo que o declara (parágrafo único do art. 42), suprima-se a alusão a dever o juiz atender às condições pessoais e econômicas do condenado, a qual aparece quase de todo repetida no art. 51 (8), onde se recomenda que na fixação da pena de multa o juiz tenha em conta, principalmente, "a situação econômica do condenado". Poder-se-ia acrescentar aí a referência às "condições pessoais", e estaria dito tudo.

10. - No capítulo atinente à aplicação da pena, o art. 50 (9) do anteprojeto não melhora o disposto no art. 42 (10) do Código Penal. A norma em vigor só tem uma redundância, e desculpável como fôrça de expressâo, dada a proximidade dos vocábulos. Mandando considere o magistrado a personalidade do sujeito ativo, não necessitaria advertí-lo a considerar também os seus antecedentes, pois êstes ilustram aquela.

$E^{\prime}$, de modo geral, um dispositivo satisfatório, que compendia com tôda a apropriada elasticidade os critérios judiciais de fixação da pena. Já o art. 50 do anteprojeto entra em pormenores escusados: falando de periculosidade maior ou menor, específica dispensàvelmente a capacidade de delinquir. Ao alto, alude à personalidade do réu, e, após longa digressão sôbre outros elementos, alude aos antecedentes do réu. Seria preferível desdobrar em dois itens o preceito, situando no primeiro, conjuntamente, os elementos de avaliação objetiva e, no segundo, os de avaliação subjetiva, o que tornaria mais admissível a referência aos antecedentes, como continuação da referência à personalidade.

Também acredito que, como índice para dosagem da pena, de muito pouco vale, ou mesmo nada, a alusão ao "meio social em que vive" o acusado. Difícilmente saberá o juiz se com essa indagação terá que aumentar ou diminuir a pena.

E ainda: em preceito dessa maneira extenso, representa certamente uma inadvertência, a ser sanada, a omissão de um dado impostergável na adequação da pena: os motivos determinantes.

11. - Na lista de agravantes obrigatórias o art. 52 do anteprojeto repete, com ligeiras modificações formais, o art. 44 do atual Código. O que mais se nota é a falta da embriaguez preordenada. Convenha-se em que a perda não é irreparável, porque o juiz de algum modo poderá carregar, por outra via, contra o delinquente que se

(8) - Art. 51 - Na fixação da pena de multa, o juiz deve ter em conta, principalmente, a situação econômica do condenado.

(9) - Art. 50 - Para fixação da pena privativa de liberdade, o juiz aprecia a gravidade do crime praticado e a personalidade do réu, devendo ter em conta a maior ou menor extensão do dano ou perigo de dano, os meios empregados, o modo de execução, as circunstâncias de tempo e lugar, a intensidade do dolo ou gráu da culpa, os antecedentes do réu, sua maior ou menor periculosidade ou capacidade de delinquir, meio social em que vive, e sua atitude de insensibilidade, indiferença ou arrependimento após o crime.

(10) - Art. 42, Código Penal - Compete ao juiz, atendendo aos antecedentes e à personalidade do agente, à intensidade do dolo ou gráu da culpa, aos motivos, às circunstâncias e consequências do crime" etc. 
embriaga de propósito para delinquir, o intenso dolo com que procede. Mas não há razão ponderável para o cancelamento efetuado. Se o anteproịeto trasladou tudo o que, como circunstâncias obrigatórias, consta do Código, por que saltar o item da atual letra " $c$ " do art. 48? Um anteprojeto de reforma da legislação penal brasileira só deve abolir, daquilo que nos rege, o que a experiência tenha apontado como merecedor de supressão, e tal não ocorre com a agravan te em aprêço. Até pelo contrário. A sua inclusão suscitou louvores.

12. - O critério agora perfilhado tem a sua história. $E^{\prime}$ um reflexo da inaceitável diretriz do anteproịeto acêrca do problema da embriaguez. O severo mecanismo penal vigente nesse assunto comporta certa discussão quanto aos princípios que o nortearam, mas não há dúvida de que é eficiente à luz da política criminal. O anteprojeto, contudo, tende a esfrangalhá-lo. Constituiria um descalabro a adoção das suas regras em nosso país, onde os despautérios do tribunal do juri devem estar sempre gravitando no espírito dos reformadores.

Quando o Código se reporta à embriaguez voluntária ou culposa, é para realçar, prudentemente, que não the confere, mesmo quando completa, nenhuma influência liberatória da responsabilidade, que permanece íntegra. Não há, pois, que distinguir entre voluntária e culposa, mesmo porque a linha de separação é tênue e sujeita a tôda sorte de incertezas na prática. Como saber se o ébrio terá querido realmente embriagar-se (embriaguez voluntária) ou apenas ingerir a bebida alcoólica que o embriagou (embriaguez culposa)? Não é possível edificar sôbre o frágil alicerce dessa distinção qualquer diferença no regime repressivo.

Pois o anteprojeto, embora sem mencionar expressamente a embriaguez culposa, diz, de forma indireta, no art. 31 (11), que a embriaguez involuntária - expressão que abrange a culposa exclui a responsabilidade, mesmo quando incompleta. Não se justifica semelhante concessão, máxime ante a dificuldade de averiguar se a embriaguez é voluntária ou involuntária.

$E^{\prime}$ nessa ordem de idéias que o anteprojeto afasta a embriaguez preordenada do rol das agravantes, para só enquadrá-la como indicativa de dolo comum (art. $31, \S 1 .^{\circ}$ ) (12). E no parágrafo imediato (13) premeia, por exemplo, com a pena da culpa restrita o homicídio executado com ferocidade pelo indivíduo completamente embriagado que, anteriormente, previu que poderia vir a cometer o crime. "Previu“ é situação psicológica de quem pode ter querido o crime. Sendo

(11) - Art. 31 - A embriaguez, pelo álcool ou substância de efeitos análogos, ainda quando completa, não exclui a responsabilidade, salvo quando fortuita ou involuntária.

(12) - § 1.0 - Se a embriaguez foi intencionalmente procurada para a prática do crime, o agente é punivel a título de dolo.

(13) - § 2.0 - Se, embora não preordenada, a embriaguez é voluntária e completa, e o agente previu ou podia prever que, em tal estado, poderia vir a cometer crime, a pena é aplicável a título de culpa, se a êste título é punível o fato. 
assás difícil apurar-se se o que houve foi previsão ou, um pouco mais que isso, volição o que adviria é um autêntica licença para o homicídio, ante a benignidade da pena reservada à simples imprudência.

Lembre-se que a simulação de uma profundidade maior no estado de embriaguez é acessível até a um imitador sem grande talento e que quase sempre é a prova testemunhal que decide da ques†ão.

13. - Sugiro ligeira emenda de redação ao § $1 .^{\circ}$ do art. 53 (14), que estabelece não se configurar reincidência quando entre a extinção da pena e o crime posterior ocorreu período de tempo "superior a cinco anos". Será melhor a fórmula "igual ou superior a cinco anos", em simetria com o art. 71, relativo ao livramento condicional, unde se diz "igual ou superior a dois anos".

Mas cinco anos não serão pouco para tão relevante consequência? Deixo aí a pergunta. Por mim, exigiria dez anos. Há certo ilogismo em condescender por demais, nessa passagem, com a reincidência, quando, adiante, se reage drásticamente contra ela, e até contra a recaída no crime sem reincidência, através das sanções endereçadas ao criminoso habitual.

14. - O sistema de aplicação da pena como está regulado no Código Penal de 1940 tem uma falha, que foi perdendo a importância com o passar do tempo. Comportou acirrada controvérsia sôbre a quantidade de fases a serem percorridas pelo juiz no seu trabalho. Ao contrário da exegese sustentada pelo eminente autor do atual anteprojeto, predominou a compreensão de que duas, tão-só, são essas fases, e isso quando existem causas de aumento ou de diminuição ajustadas ao caso. A proposta de NELSON HUNGRIA, desejando que o magistrado secionasse mais a sua tarefa, não emanava imperativamente dos textos e complicava desnecessàriamente o que podia ser legítimamente simplificado.

O anteprojeto, neste particular, tem, por igual, o defeito do Código quanto à falta de clareza. E de método. Pensa que deviam estar inscritos dispositivos que em linha reta explicassem como deve o juiz

(14) - Art. 53 - Verifica-se a reincidência quando o agente comete novo crime, depois de transitar em julgado a sentença que, no país ou no estrangeiro, o tenha condenado por crime anterior.

$\S 1.0$ - Não se toma em conta, para o efeito de reincidência, a condenação anterior, se entre a data do cumprimento ou extinção da pena e o crime posterior decorreu período de tempo superior a cinco anos.

(15) - Art. 60 - Em se tratando de criminoso habitual ou por tendência, a pena ou soma de penas pode ser aumentada até o dôbro, salvo o disposto no art. 58.

$\S 1.0$ - Considera-se criminoso habitual aquêle que:

a) reincide pela segunda vez na prática de crime doloso da mesma natureza, punível com pena privativa de liberdade;

b) embora sem condenação anterior, comete sucessivamente, em período não superior a cinco anos, quatro ou mais crimes da mesma natureza, puníveis com pena privativa de liberdade, e demonstra, pelas suas condições de vida e pelas circunstâncias dos fatos apreciados em conjunto, acentuada inclinação para tais crimes. 
proceder. As normas traçadas dizem as coisas através de sugestõe's ou inferências, nem sempre seguras.

Repete-se o dispositivo do art. 50 do Código, que tem a sua explicação, trabalhosa, mas que soa como algo lapalissiano: "A pena que tenha de ser aumentada ou diminuída, de quantidade fixa ou dentro de determinados limites, é a que juiz aplicaria se não existisse causa de aumento ou de diminuição". No anteprojeto, o correlato art. 59 está assim redigido: "A pena que tenha de ser aumentada ou diminuída, de quantidade fixa ou dentro de determinados limites, é a que o juiz aplicaria, se não existisse a circunstância ou causa que importe o aumento ou diminuição".

A redação não é esclarecedora do genuino intuito da advertên. cia, no qual só se penetra após muito pensar e repensar. $O$ dispositivo quer aludir à pena-base, como suporte de todo e qualquer aumento e diminuição, quer decorra de circunstâncias (agravantes ou atenuantes), quer decorra de causas de aumento ou diminuição.

No Código, há diferença nítida entre tais circunstâncias, de um lado, e causas de aumento ou diminuição, de outro lado: estas obrigando, e aquelas não, a aumentos ou diminuições em quantidade fixa ou compreendida entre limites extremos (v. g., um a dois terços, de um sexto até metade; o dôbro, etc.). No anteprojeto, essa diferenciação vem obscurecida, porque as circunstâncias também acarretam aumento ou diminuição entre limites extremos: "entre um quinto e um têrço" (art. 55).

Exatamente porque assim operam, não podem atuar juntamente com os critérios judiciais do art. 50 (correspondente ao art. 42 do Código) e de conseguinte se impõe agora o sistema tricotômico de etapas.

Outra diferença que o anteprojeto firma entre circunstâncias e causas de aumento ou diminuição é que, tal qual no Código, aquelas não afetam, e estas podem fazê-lo, os limites extremos das penas cominadas para a figura delituosa.

15. - Não me parece que tenha havido aperfeiçoamento, no sistema proposto. A excessiva decomposição da tarefa de dosagem da pena desnatura o resultado. São tão amplos os critérios contidos no primeiro dispositivo do capítulo (o das circunstâncias chamadas comumente de "judiciais"), que a autonomia do acréscimo ou diminuição atinente a circunstâncias agravantes e atenuantes pròpriamente ditas induzirá o juiz a computar mais de uma vez o mesmo elemento de exasperação ou abrandamento: ao estribar-se no art. 50 (análogo, repito, ao art. 42 vigente) e ao sopesar as agravantes e atenuantes. Por exemplo, de acôrdo com o art. 50, aumenta a pena do réu que lhe parece ser um indivíduo perigoso e porque considera "os meios empregados" na execução do crime. Na segunda etapa, aumenta-lhe a pena porque o réu empregou meio "cruel", revelador de periculosidade... . $E^{\prime}$ a isso que conduz a tricotomia. 
Contraditóriamente, o anteprojeto mantém, do Código, o atributo de obrigatoriedade das circunstâncias agravantes e atenuantes (refere o seu art. 52 serem "circunstâncias que sempre agravam a pena" e diz o art. 54 serem "circunstâncias que sempre atenuam a pena) e, linhas após, explica, no art. 56, que se ocorrer mais de uma agravante ou mais de uma atenuante, "o juiz se limitará a uma só agravação ou a uma só atenuação". Portanto, já não são obrigatórias.

E a dispensa não é convincente. Um "tarado", sem ser irresponsável, reincide (agravante do art. 52, n. ${ }^{\circ} \mathrm{I}$ ) em crime sexual contra criança (agravante do art. 52, n. $\left.{ }^{\circ} \mathrm{II},{ }^{\prime \prime} \mathrm{i}^{\prime \prime}\right)$. Por que um só aumento de pena? E como respeitar a restrição imposta ao juiz se no art. 50 êle encontrará a maior liberdade para a escolha de pesada penabase?

Não se percebe por que não é tolerada a coexistência de agravantes ou a de atenuantes, quando o art. 58, § único, declara que, "no concurso de causas especiais de aumento ou de diminuição previstas na Parte Especial, pode o juiz limitar-se a um só aumento ou a uma só diminuição", o que Ihe faculta aumentar ou diminuir a pena duas ou mais vêzes.

16. - Outro ponto em que, no meu modo de ver, o anteprojeto discrepou do Código sem vantagem, é o art. 57 daquele, assim concebido: "No concurso de agravantes ou atenuantes, se, conforme razoável apreciação do juiz, preponderam as agravantes, são consideradas inexistentes as atenuantes; se, ao contrário, preponderam estas, ficam excluídas aquelas. Se há equivalência entre umas e outras, é como se não tivessem ocorrido".

Tôda apreciação do juiz o legislador deve presumir "razoável". sendo pleonástico o qualificativo. A supressão de uma agravante obrigatória por existir uma atenuante obrigatória, ou vice-versa, infringe a realidade complexa que o juiz deve ter em mente ao graduar a pena, e afinal tem mesmo, queira ou não queira o art. $5 \%$, sob o amparo do flexível enunciado do art. 50. Além de que, inesperadamente, uma ou outra deixa de ser "obrigatória".

O anteprojeto não elucida acêrca de qualquer paradigma para a primazia ou compensação de umas circunstâncias relativamente a outras. Podia, pelo menos, ter reproduzido o que se lê no art. 49 do Código, que confere preponderância aos índices subjetivos, - motivos determinantes e personalidade.

Viu-se que, estranhamente, várias agravantes se reduzem a uma só, e várias atenuantes se reduzem, por seu turno, a uma só (art. 56). Se um reincidente perpetrar por motivo torpe crime contra irmão, assim incorrendo em três agravantes, ter-se-á no cálculo da pena uma só agravante. Imagine-se que o delinquente seja menor. As três agravantes, reduzidas por lei a uma só, compensam-se com a 
atenuante? Parece que o número das circunstâncias não devia ser excluído.

17. - Na conceituação de criminoso habitual (15) o anteprojeto, cogitando da reiteração criminal, com ou sem verdadeira reincidência, tem em aprêço crimes dolosos, da mesma natureza, puníveis com pena privativa de liberdade. Mas todos os crimes são puníveis com pena privativa de liberdade.

18. - Não são entre si harmônicos os arts. 59 e 60 do anteprojeto. O primeiro, como ficou frisado, só pode ter a significação de determinar que os acréscimos ou diminuições provenientes das chamadas causas de aumento ou de diminuição de pena operem sôbre a pena-base. Ou, exemplificando: se se estipula um aumento de um sexto, tal aumento não incide sôbre a quantidade penal resultante do acréscimo correspondente a uma agravante obrigatória, e sim sôbre a quantidade penal a que se chegara antes de agir a agravante.

Assim fixado o alcance do art. 59, desconcertantemente acrescenta o art. 60: "Em se tratando de criminoso habitual ou por tendência, a pena ou soma de penas pode ser aumentada até o dôbro, salvo o disposto no art. 58". Já aqui se encontra uma causa de aumento de pena ("o dôbro") agindo depois da ação de possível agravante, porquanto as palavras que sublinhei "soma de penas" pressupõem penas definitivamente impostas.

19. - "Considera-se criminoso por tendência - define o art. $60, \S 2 .^{\circ}$, do anteprojeto - aquêle que comete homicídio, tentativa de homicídio ou lesão corporal grave, e, pelos motivos determinantes e meios ou modo de execução, revela extraordinária torpeza, perversão ou malvadez".

Note-se a referência aos motivos determinantes, a qual escapou à previsão fundamental do art. 50. Entendo que a fórmula devia abranger uma alusão aos crimes sexuais a que se vinculem alguns dos atos criminosos contemplados.

20. - A maior novidade do anteproịeto quanto ao concurso de crimes é a equiparação do concurso formal ao concurso material.

Não nego que essa tendência tem por si certos argumentos. Mas não me parece merecedora de acolhida, sôbretudo quando se conserva a excessiva liberalidade do Código na configuração do crime continuado.

Sobreviverá es ${ }^{\dagger} a$ disparidade. O delinqüente pratica, através de múltiplas ações, crimes autônomos que, graças ao preceito em extremo permissivo acêrca da continuidade, são unificados para o efeito de uma só pena. Nem ao menos, consoante a letra da lei, repetida no anteprojeto, se exige unidade de desígnio. Portanto, ações variadas, com destacados desígnios, - pena única. Agora, se o agente comete com uma só ação e com um só intuito criminoso duas infrações, deve ser punido através da soma de penas. Há lógica? Não. 